\title{
Antibacterial Films of Alginate-CoNi-Coated Cellulose Paper Stabilized Co NPs for Dyes and Nitrophenol Degradation
}

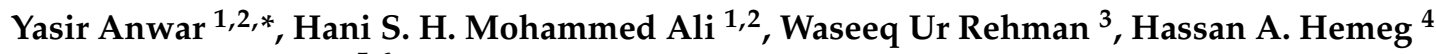 \\ and Shahid Ali Khan 5,6,* \\ 1 Department of Biological Sciences, Faculty of Science, King Abdulaziz University, P.O. Box 80203, \\ Jeddah 21589, Saudi Arabia; haniolfat@gmail.com \\ 2 Princess Dr. Najla Bint Saud Al-Saud Center for Excellence Research in Biotechnology, King Abdulaziz \\ University, P.O. Box 80203, Jeddah 21589, Saudi Arabia \\ 3 Department of Chemistry, Government Post Graduate College Nowshera, Nowshera 24100, Pakistan; \\ gwaseeq@gmail.com \\ 4 Department of Medical Laboratory Technology, College of Applied Medical Sciences, Taibah University, \\ Almadina Almunawra 30001, Saudi Arabia; hasanhemeg@hotmail.com \\ 5 Center of Excellence for Advanced Materials Research (CEAMR), King Abdulaziz University, P.O. Box 80203, \\ Jeddah 21589, Saudi Arabia \\ 6 Department of Chemistry, University of Swabi, Swabi Anbar, Swabi 23561, Pakistan \\ * Correspondence: yasirpcsir2006@gmail.com (Y.A.); skhan@uoswabi.edu.pk (S.A.K.)
}

check for updates

Citation: Anwar, Y.;

Mohammed Ali, H.S.H.;

Rehman, W.U.; Hemeg, H.A.;

Khan, S.A. Antibacterial Films of Alginate-CoNi-Coated Cellulose Paper Stabilized Co NPs for Dyes and Nitrophenol Degradation. Polymers 2021, 13, 4122. https://doi.org/ $10.3390 /$ polym 13234122

Academic Editor: Arn Mignon

Received: 30 October 2021

Accepted: 22 November 2021

Published: 26 November 2021

Publisher's Note: MDPI stays neutral with regard to jurisdictional claims in published maps and institutional affiliations.

Copyright: (c) 2021 by the authors. Licensee MDPI, Basel, Switzerland. This article is an open access article distributed under the terms and conditions of the Creative Commons Attribution (CC BY) license (https:/ / creativecommons.org/licenses/by/ $4.0 /)$.

\begin{abstract}
The development of a solid substrate for the support and stabilization of zero-valent metal nanoparticles (NPs) is the heart of the catalyst system. In the current embodiment, we have prepared solid support comprise of alginate-coated cellulose filter paper (Alg/FP) for the synthesis and stabilization of Co nanoparticles (NPs) named as Alg/FP@Co NPs. Furthermore, Alginate polymer was blended with 1 and 2 weight percent of CoNi NPs to make Alg-CoNi1/FP and Alg$\mathrm{CoNi} 2 / \mathrm{FP}$, respectively. All these stabilizing matrixes were used as dip-catalyst for the degradation of azo dyes and reduction of 4-nitrophenol (4NP). The effect of initial dye concentration, amount of $\mathrm{NaBH}_{4}$, and catalyst dosage was assessed for the degradation of Congo red (CR) dye by using Alg-CoNi2/FP@Co NPs. Results indicated that the highest $k_{\text {app }}$ value $\left(3.63 \times 10^{-1} \mathrm{~min}^{-1}\right)$ was exhibited by Alg-CoNi2/FP@Co NPs and lowest by Alg/FP@Co NPs against the discoloration of CR dye. Furthermore, it was concluded that Alg-CoNi2/FP@Co NPs exhibited strong catalyst activity against $\mathrm{CR}$, and methyl orange dye (MO) degradation as well as $4 \mathrm{NP}$ reduction. Antibacterial activity of the prepared composites was also investigated and the highest 1 activity was shown by Alg-CoNi2/FP@Co NPs, which inhibit $2.5 \mathrm{~cm}$ zone of bacteria compared to other catalysts.
\end{abstract}

Keywords: alginate; CoNi nanocomposite; cellulose paper; antibacterial potential; degradation

\section{Introduction}

Nanoscience received much interest in recent years due to their vast applications in sensing, drug delivery, antimicrobial activity, coating, bio-imaging, environmental remediation, and biomedical applications [1-6]. Besides their major applications in various technological sectors, they are used as catalysts in many industrial and chemical reactions like hydrogen production [7], oxygen evolution reaction, organic reactions [8], and nitroaromatics reduction [9-12]. The above diverse applications of metallic nanoparticles are because of their high surface to volume ratio, high surface energy, and small quantum size effect [13]. The quantum size effect gives an amazing reduction in the particle size of the nanoparticles beyond the threshold limit and leads to the change in the electronic environment of the particle. Owing to the change in the electronic environment, small particle size, high surface area, and high surface energy lead to an abrupt increase in particle activity. However, due to the high energy associated with the particle, there exist some drawbacks with the usage of these particles as the catalyst. For instance, aggregation 
and agglomeration of the particles are due to the physical entanglement and Wander Waal's forces [14]. The second most common problem in nanoparticles research is their separation after the reaction completion. Both the problems can be overcome by the use of a solid matrix that not only avoids particle aggregation, but also is easily separated from the reaction mixture. The separation of a catalyst by an easy method from the reaction mixture at any time is called a dip-catalyst. Moreover, the use of a solid support improves the stability of the nanoparticles. For example, using solid support not only avoids aggregation, but also prevents the leaching of nanoparticles, which otherwise cause's environmental issues. Many solid supports have been used for the stabilization of nanoparticles such as carbon [15], metal oxide [16], inorganic (e.g., silica (Li et al., 2013)), or organic materials [17]. Organic solid support is the most frequently used solid support for this purpose due to its inert nature to the reaction and ease of derivatization by introducing new functionality to the host material. However, among all these supporting materials, polymer-supported substrate for nanoparticles stabilization is one of the most important systems. For instance, Pd nanoparticles have been supported on polymethyl methacrylate spheres [18], and fabricated polystyrene microspheres supported Pt nanoparticles are examples of this [19]. Some approaches have been applied to use cellulose polymer as solid support for various metal nanoparticles. For example, some researchers have used cellulose cotton in the form of filter paper for metallic nanoparticle stabilization [20]. Cellulose is one of the most abundant natural organic polymers and is used in composite and packaging materials, and are also used in textile industries. The $\beta 1,4$ glycoside linked the $\beta$-D-anhydroglucopyranose monomers through one to four linkages. This linear cellulose molecule has three $-\mathrm{OH}$ groups in its monomer unit, which are responsible for the stabilization of metal nanoparticles. Furthermore, the cellulose polymer-supported NPs act as a dip-catalyst, and one can remove the catalyst from the reaction medium easily [21]. Although, cellulose microfibers have multiple-OH groups in their polymer network, but low process-ability, it was not considered for using directly as a stabilizing matrix for Co NPs. Furthermore, the alginate polymer swells easily and demonstrated a strong gelling characteristics to make hydrogels. Therefore, both cellulose microfibers and alginate polymer provide a good platform for the stabilization of NPs. Moreover, the use of alginate biopolymer to coat the surface of cellulose paper has markedly enhanced the active functionalities that further stabilize the metal nanoparticles. For instance, the presence of $-\mathrm{OH}$ and $-\mathrm{COOH}$ groups in the alginate biopolymer further increases the stabilization of the Co NPs [22-24]. It is reported that inorganic polymer hybrid material greatly enhanced the properties of the materials [25]. Therefore, CoNi nanocomposite was incorporated in the alginate polymer host material to achieve a hybrid composite.

Mostly the supported nanoparticles were used for the degradation of organic pollutants in an aqueous medium. Nitrophenols and azo dyes are among the most noticeable organic pollutants. The two common nitrophenols are 2- and 4-nitrophenols and various industries produce them in a large amount. If an industry produces one nitrophenol, the other will be formed in small quantities and vice versa. Both nitrophenols find large applications in pharmaceutical, agriculture, fabric, dye, cosmetic, and explosive industries. Nitrophenols are health hazards and many health issues are associated with them, for instance, high exposure to them can irritate eyes, nose, throat, skin, and possibly damage the eye. Furthermore, exposure to 4-nitrophenols can cause stomach disorders, enhance heartbeat, and may affect the central nervous system [26,27].

Furthermore, azo dyes contributed two-thirds of all the synthetic dyes and are used in large amounts in the pharmaceutical industry [28-30]. They are used in the pharmaceutical industry to color various drugs; however, carcinogenic and mutagenic activities of many azo dyes are reported in the literature. Azo dyes also find applications in the fabric and cosmetics industries. Moreover, the carcinogenic effect of most azo dyes depends on the structure of dye molecule and the way they are degraded [31,32]. 
In the current study, we have prepared alginate-based cellulose filter paper (FP) as solid support for $t$ zero-valent Co NPs and used it in the degradation of CR and MO dyes as well as $4 \mathrm{NP}$ in the presence of borohydride in an aqueous medium.

\section{Experimental Section}

2.1. Reagents and Materials

Congo red, (CAS no. 573-58-0) methyl orange, (CAS no. 547-58-0), and $\mathrm{NaBH}_{4}$ (CAS no. 16940-66-2) were purchased from DAEJUNG Company (Sasang-gu, Busan, Korea). Similarly, other chemicals such as, $\mathrm{NaOH}, \mathrm{CoCl}_{2} \cdot 6 \mathrm{H}_{2} \mathrm{O}$, and $\mathrm{NiCl}_{2} \cdot 6 \mathrm{H}_{2} \mathrm{O}$ were acquired from Sigma Aldrich (Kawasaki, Kanagawa, Japan), and deionized water was used throughout the experiment. Sodium Alginate polymer (CAS no. 9005-38-3) was purchased from DAEJUNG Company (Sasang-gu, Busan, Korea), while Whatman filter paper was used as a source of cellulose paper and was obtained from Sigma Aldrich (Kawasaki, Kanagawa, Japan).

\subsection{Synthesis of Catalyst}

\subsubsection{Synthesis of CoNi Nanocomposite}

CoNi nanocomposite was synthesized via the sol-gel method using the previous procedure [20-22]. An equal amount of $0.5 \mathrm{mM}$ solution of $\mathrm{CoCl}_{2} \cdot 6 \mathrm{H}_{2} \mathrm{O}$, and $\mathrm{NiCl}_{2} \cdot 6 \mathrm{H}_{2} \mathrm{O}$ was mixed in the stoichiometric ratio in a $1 \mathrm{~L}$ flask and mixed for $30 \mathrm{~min}$. After that, a dilute solution of $\mathrm{NaOH}$ was added to the solution till $\mathrm{pH} 10$, and heated for $7 \mathrm{~h}$ at $70{ }^{\circ} \mathrm{C}$ with uniform magnetic stirring. The product formed was washed with a 1:4 ethanol-water mixture, and heated in an oven for $8 \mathrm{~h}$ at $50{ }^{\circ} \mathrm{C}$. The dried product was calcined and activated at $400{ }^{\circ} \mathrm{C}$ for $6 \mathrm{~h}$.

\subsubsection{Preparation of Alg/FP}

The alginate polymer $(2 \mathrm{~g})$ was thoroughly dispersed in $50 \mathrm{~mL}$ distilled water through constant stirring to make a viscous solution. After that, 5 pieces $\left(2 \times 6 \mathrm{~cm}^{2}\right)$ of Whatman filter paper (FP) were put in the alginate solution for $6 \mathrm{~h}$ to coat the FP and then dried at room temperature.

\subsubsection{Preparation of Alg-CoNi1/FP and Alg-CoNi2/FP}

Both Alg-CoNi1/FP and Alg-CoNi2/FP were synthesized in three steps.

In the first step, $2 \mathrm{~g}$ alginate polymer was dissolved in $50 \mathrm{~mL}$ distilled water in two separate beakers to make their viscous solutions. In the second step, 1 and 2 weight $\%$ of CoNi composite was dispersed in each separate beaker and homogenized through continuous stirring, respectively. In the third step, the FP was placed in the above mixture for $6 \mathrm{~h}$ and then dried at room temperature.

\subsubsection{Preparation of Alg-CoNi1/FP@Co and Alg-CoNi2/FP@Co NPs}

The Alg-CoNi1/FP and Alg-CoNi2/FP substrate were placed in $0.5 \mathrm{mM} \mathrm{Co}$ (II) salt solution for $6 \mathrm{~h}$ and then rinsed with distilled water and dried. The dried Alg-CoNi1/FP and Alg-CoNi2/FP adsorbed Co (II) ions were dipped in $0.1 \mathrm{mM} \mathrm{NaBH}_{4}$ fresh solution for $5 \mathrm{~min}$, which converted Co ions to zero-valent $\mathrm{Co} \mathrm{NPs}\left(\mathrm{Co}^{0}\right)$. The as-synthesized Co NPs were directly used for the antibacterial studies and degradation of azo dyes or $4 \mathrm{NP}$ reduction as shown in Scheme 1.

The following equation indicated the conversion of $\mathrm{Co}$ (II) ions to their $\mathrm{Co}^{0} \mathrm{NPs}$ [33].

$$
\begin{gathered}
\mathrm{Co}^{+2}+\mathrm{BH}_{4}^{-}+3 \mathrm{H}_{2} \mathrm{O}+2 \mathrm{e}^{-} \rightarrow \mathrm{Co}^{0}+\mathrm{H}_{3} \mathrm{BO}_{3}+7 \mathrm{H}^{+} \\
3 \mathrm{Co}^{0}+6 \mathrm{H}^{+} \rightarrow 3 \mathrm{Co}^{+2}+3 \mathrm{H}_{2}
\end{gathered}
$$

Both $\mathrm{Co}^{+2}$ and $\mathrm{Co}^{0}$ were supported on $\mathrm{Alg} / \mathrm{FP}, \mathrm{Alg}-\mathrm{CoNi} 1 / \mathrm{FP}$, and Alg-CoNi2/FP solid substrate. 


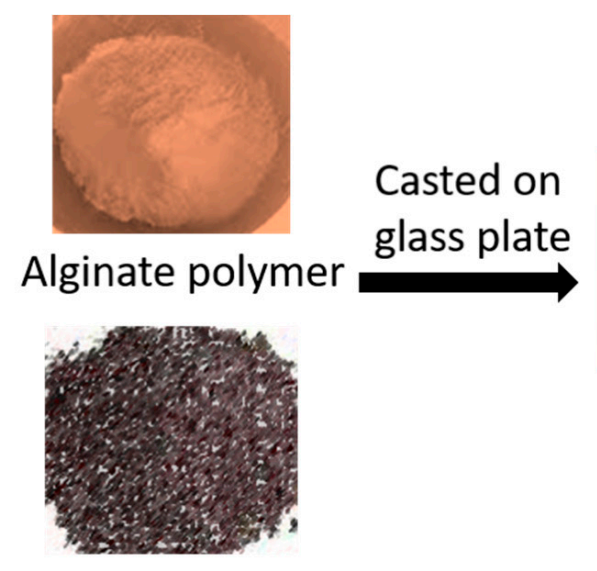

\section{Co-Ni nanocomposite}
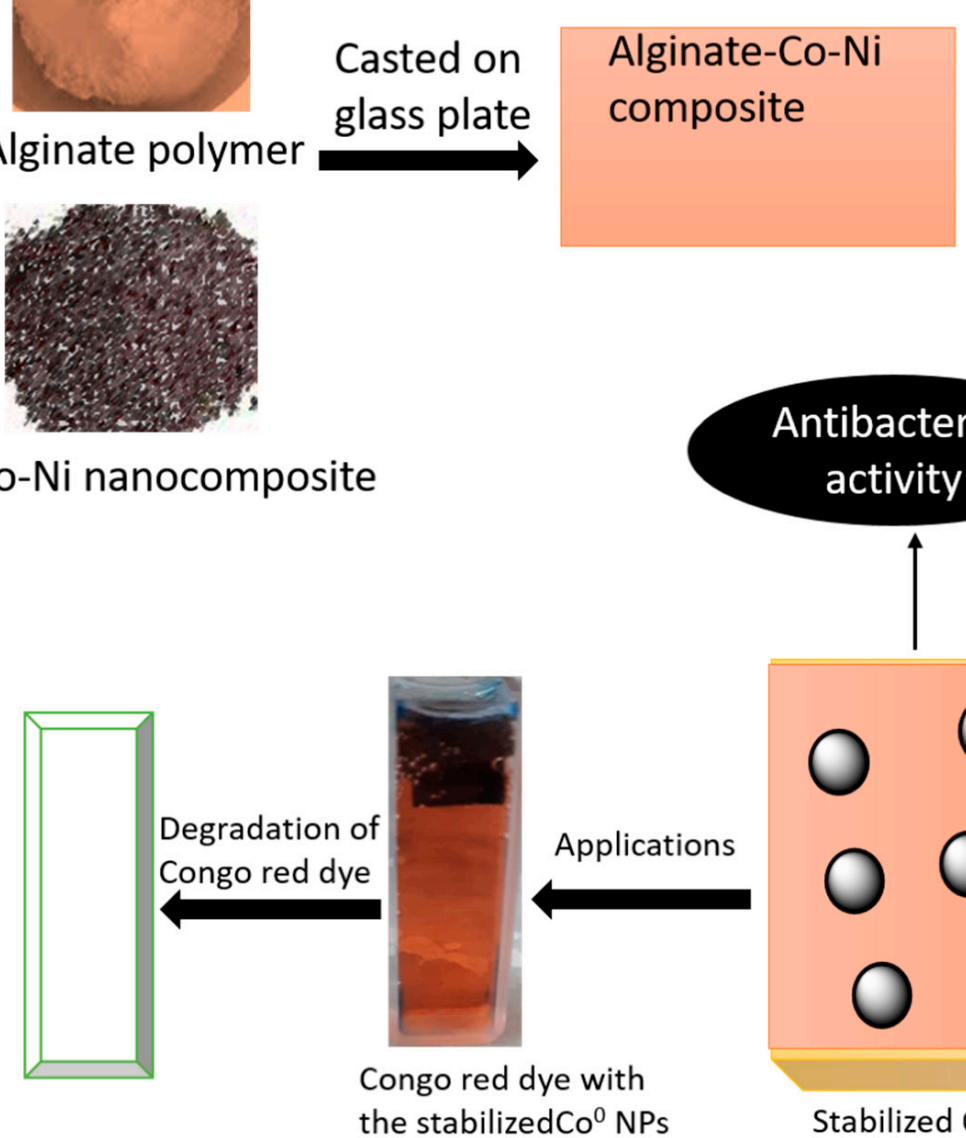

Alginate-Co-Ni coated cellulose filter paper

\section{Antibacterial activity}

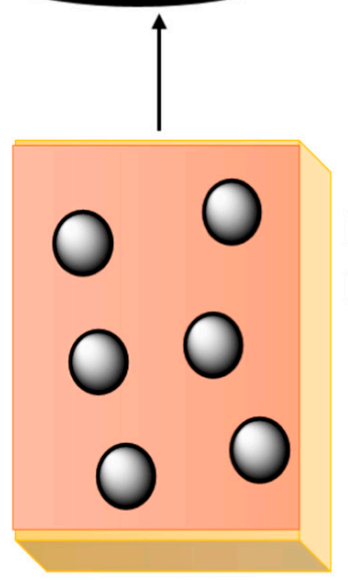

Stabilized $\mathrm{Co}^{0} \mathrm{NPs}$
Alginate-CoNi coated

Cellulose filter paper

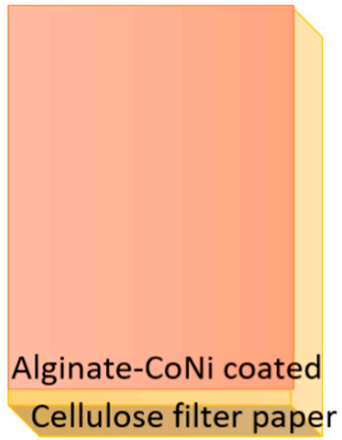

immersion in Co

(II) solution

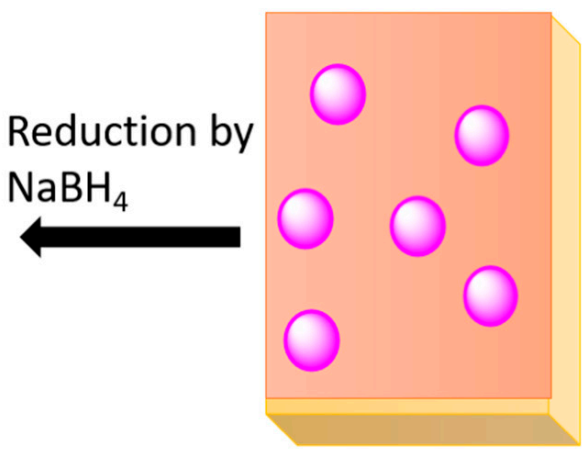

Adsorption of Co (II) ions

Scheme 1. Pictorial representation of the preparation of Alg-CoNi/FP@Co NPs and their applications against bacterial inhibition and degradation of dyes.

\subsection{Antibacterial Activity}

The antibacterial potential of Alg/FP, Alg/FP@Co, Alg-CoNi1/FP@Co, and AlgCoNi2/FP@Co NPs was evaluated on a muller Hinton agar plates against $B$. subtilis. The antibacterial method was based on the Kirby-Bauer disk diffusion method with minor changes in the procedure [34]. The plates were prepared, sterilized, solidified, and then the culture of $B$. subtilis was spread thoroughly via a sterilized spreader on the whole plate. After that, each catalyst was cut in a specified dimension and then placed in the bacterial zone. The plates were placed at $37^{\circ} \mathrm{C}$ for $24 \mathrm{~h}$. After incubation, the zone of inhibition was measured. The experiments were performed in triplicate and the performance of the catalysts was determined by calculating the mean zone of inhibition around the nutrient agar disk.

\subsection{Pollutants Degradation Experiment}

All three catalysts were applied for the degradation of azo dyes and reduction of $4 \mathrm{NP}$. The concentration of both dyes was $0.07 \mathrm{mM}$. In the batch experiment, $3 \mathrm{~mL}$ of each dye solution was put in a quartz cuvette with the addition of $0.5 \mathrm{~mL}$ of $\mathrm{NaBH}_{4}$ solution and $25 \mathrm{mg}$ of each catalyst. After that, the reaction was constantly monitored through UV-Vis spectrophotometer with a $1 \mathrm{~min}$ interval time. The decrease in absorbance at 495 and $464 \mathrm{~nm}$ for $\mathrm{CR}$ and $\mathrm{MO}$ dyes were recorded, respectively, until complete discoloration. The effect of initial dye concentration, $\mathrm{NaBH}_{4}$ amount, and catalyst dosage was evaluated on the degradation of CR dye. 
The degradation of dyes or nitrophenol in percent can be deduced from the following Equation (1).

$$
\% \text { reduction } / \text { degradation }=\frac{\left(\mathrm{C}_{0}-\mathrm{C}_{\mathrm{t}}\right)}{\mathrm{C}_{0}} \times 100
$$

where $C_{0}$ and $C_{t}$ represent the initial and final concentrations of the solution after passing time $t$.

While the rate constant $k_{\text {app }}$ was deduced from the linear relationship of $\ln C_{t} / C_{0}$ vs. $t$ as shown in Equation (2).

$$
\ln \frac{\mathrm{C}_{\mathrm{t}}}{\mathrm{C}_{0}}=-\mathrm{kt}+\mathrm{C}
$$

\subsection{Physiochemical Characterization}

The crystalline nature of the catalyst was performed on $X$-ray diffraction technique (HighTech) with $\mathrm{Cu} \mathrm{K} \alpha$ radiations source $(\lambda=0.154 \mathrm{~nm}$ ) having $25 \mathrm{~mA}$ current and $40 \mathrm{kV}$ voltage, while the scan range was recorded from $15-80 \mathrm{~nm}$ with step time $1 \mathrm{~s}$ and step size 0.05 degrees. FTIR was recorded on Autonuated total reflectance-Fourier transformed infrared spectroscopy machine of Thermo scientific Company from 400-4000 $\mathrm{cm}^{-1}$ range and FESEM on JEOL (JSM-7600F, Tokyo, Japan) and EDS (EDS oxford system, Oxford, UK). UV-Vis spectrophotometer of Thermo Scientific Evolution Company was used for the catalytic degradation experiment.

\section{Results and Discussion}

\subsection{Characterizations}

\subsubsection{FESEM}

The FESEM images of Alg/FP indicated the presence of alginate polymer on the surface of cellulose microfibers. Fibers are covered by a thin layer of the alginate polymer as shown in the Figure 1a. The Alg/FP@Co NPs indicated small particles on the surface of the alginate layer as well as cellulose microfibers. These small spherical particles indicated the presence of Co NPs (Figure 1c). The Alg-CoNi1/FP@Co NPs also showed a similar display of the alginate polymer covering the cellulose microfiber, where the CoNi are protruded from the alginate layer. Furthermore, Co NPs are stabilized on Alg-CoNi1/FP layer (Figure 1e). The same explanation is true for Alg-CoNi2/FP@Co as discussed for the Alg-CoNi1/FP@Co NPs (Figure 1g).

\subsubsection{EDS}

The EDS spectrum of all the catalysts is indicated in the inset of Figure 1. On the left side, the FESEM images of the catalyst are presented from which the right side elemental window are derived. For instance, Figure $1 \mathrm{~b}$ indicated FESEM images and the EDS spectrum of $\mathrm{Alg} / \mathrm{FP}$, which indicated $\mathrm{C}$ and $\mathrm{O}$ as the main element along with $\mathrm{Na}, \mathrm{Ca}$, and Si. The $\mathrm{C}$ and $\mathrm{O}$ elements are 38.59 and 49.59 by mass\%. Similarly, Alg/FP@Co NPs indicated $\mathrm{C}, \mathrm{O}$, and Co elements in 30.95, 56.74, and 4.61 by mass $\%$ (Figure $1 \mathrm{~d}$ ). The Alg-CoNi1/FP@Co NPs showing C, O, Ni, and Co elements in 31.61, 57.49, 0.13, and 2.77 by mass\%, respectively (Figure 1f). Similarly, Alg-CoNi1/FP@Co NPs C, O, Ni, and Co elements in $24.18,56.49,0.70$, and 6.35 by mass \% respectively (Figure $1 \mathrm{~h}$ ). In all the elemental windows, $\mathrm{Na}$ has appeared in different ratios because the alginate polymer is used in the form of their sodium salt. 

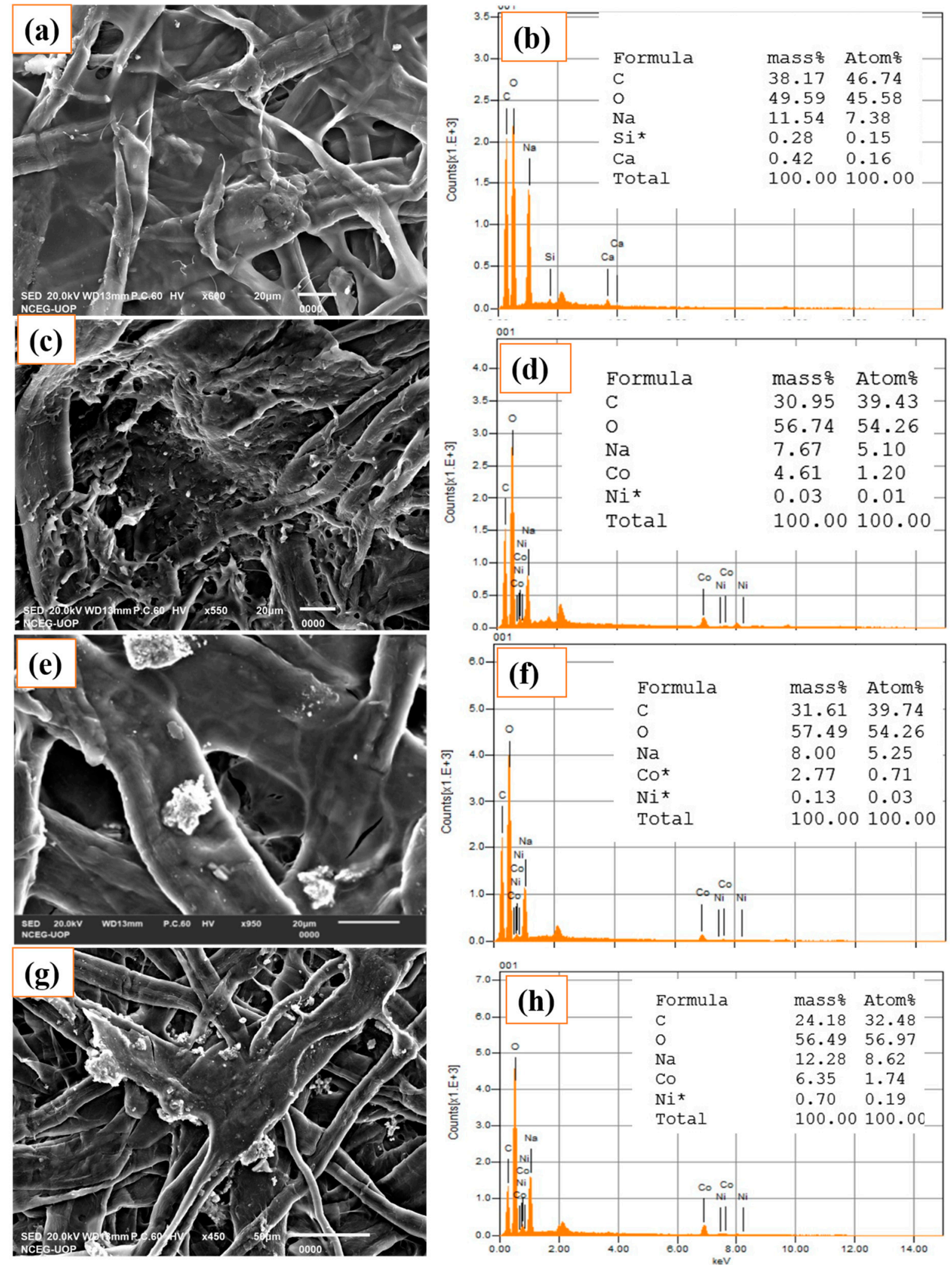

Figure 1. The left-hand side are the FESEM images that give the right-hand side elemental window with their mass and atomic percentage. The FESEM and EDS images of Alg/FP (a,b), Alg/FP@Co NPs (c,d), Alg-CoNi1/FP@Co (e,f), and Alg-CoNi2/FP@Co NPs (g,h), respectively. The star indicated in the EDS window are the Ni and Co. The EDS vertical axes indicate the scientific notation as $1 \times 10^{3}$. 


\subsubsection{FTIR}

The FTIR spectra revealed many peaks below $1600 \mathrm{~cm}^{-1}$ due to the presence of various functionalities of the polymers backbone. Similarly, there are two peaks above $1600 \mathrm{~cm}^{-1}$, which are displayed at 2897 and $3308 \mathrm{~cm}^{-1}$ due to the presence of C-H and $\mathrm{O}-\mathrm{H}$ asymmetric stretching vibrations (Figure 2a). Furthermore, the broadness of peaks at $3308 \mathrm{~cm}^{-1}$ in all catalysts is due to the presence of multiple intra or inter-molecular H-binding in alginate and cellulose microfibers [21]. The absorbance at $1605 \mathrm{~cm}^{-1}$ suggests the adsorbed water on the polymer surface, while the acetate group exhibited peak at $1489 \mathrm{~cm}^{-1}$. The acetate groups are present in both cellulose microfibers and alginate polymer host material. Moreover, the characteristic polysaccharides peaks appeared in the range of 1422-555 $\mathrm{cm}^{-1}$. For instance, peaks at 1422, 1379, 1160, and $1096 \mathrm{~cm}^{-1}$ indicated the presence of $-\mathrm{CH}_{2},-\mathrm{CH}_{3}$, and $-\mathrm{OH}$ and $\mathrm{C}-\mathrm{O}$ bending vibrations [25]. Besides, the peak in the range of $1420-1430 \mathrm{~cm}^{-1}$ suggesting the crystalline nature of polysaccharide, while the amorphous amount appeared in the range of $842 \mathrm{~cm}^{-1}$ in the polymer backbone [35]. The absorbance peak at $555 \mathrm{~cm}^{-1}$ is the characteristic of the metal-oxygen bond [36], which is prominent in the Alg-CoNi2/FP@Co NPs. The fingerprint region also appeared in the range of $800-500 \mathrm{~cm}^{-1}$, therefore, this peak also exhibited in another catalyst. The above discussion inferred that the synthesized catalysts have a polymer backbone with little difference in the absorbance peaks. The small difference in the absorbance peaks among the catalyst peaks and from the literature data is due to the interconnectivity of alginate polymer with CoNi catalyst and cellulose microfibers.
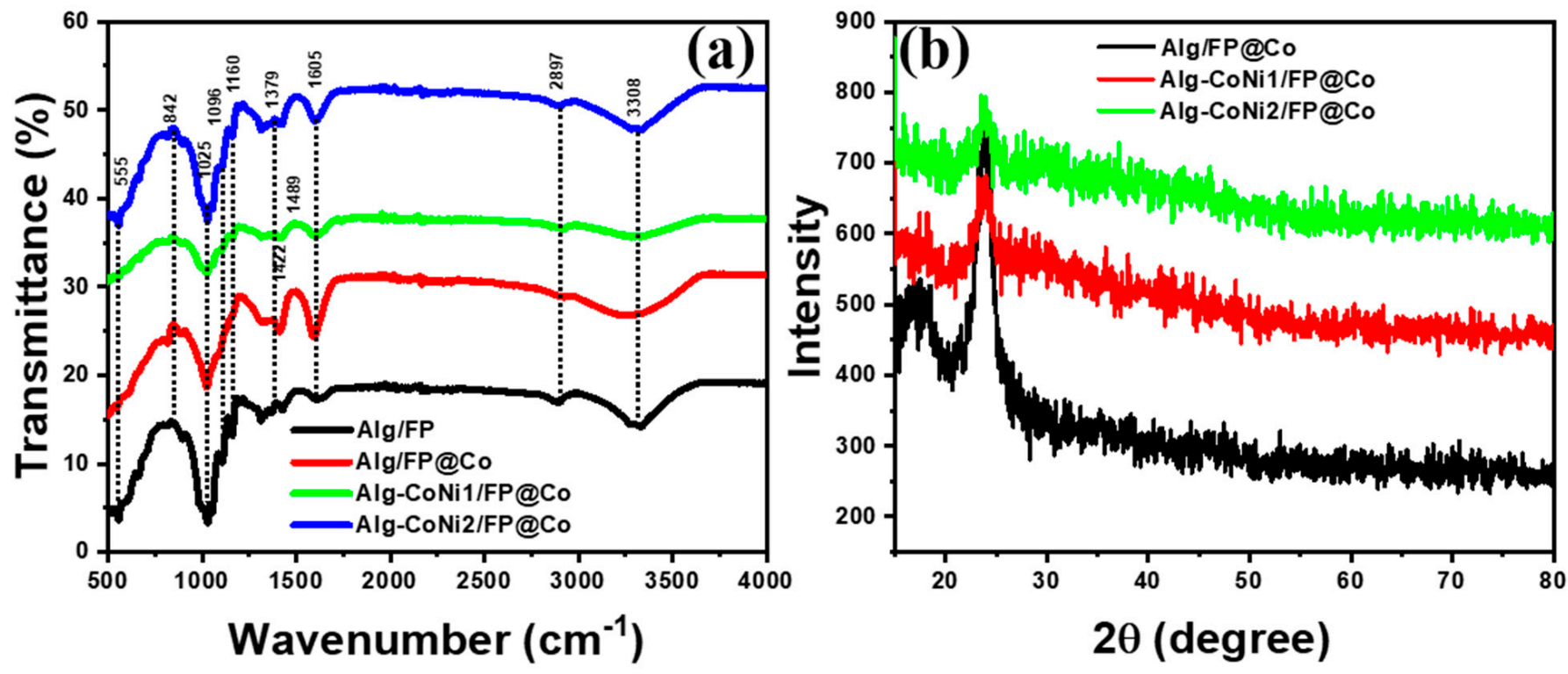

Figure 2. FTIR (a) and XRD (b) of Alg/FP, Alg-CoNi1/FP@Co, and Alg-CoNi2/FP@Co NPs.

\subsubsection{XRD}

XRD spectra indicated sharp crystalline peaks for cellulose microfibers at $2 \theta=17.0^{\circ}$ and $23.1^{\circ}$, which correspond to the crystal-I plane of cellulose microfibers at (110) and (200) planes, respectively (Figure 2b). The Co NPs did not appear in all the catalysts, suggesting their poor crystalline growth during the process at room temperature. Similar observations were also reported in the literature during the synthesis of $\mathrm{Co}$ and $\mathrm{Cu}$ NPs, respectively $[37,38]$. Therefore, we suggest that bigger particles of Co NPs formed due to aggregation.

\subsection{Antibacterial Characteristics}

Microbial contamination is a major issue in various technological fields such as the food industry, personal care products, water industry, medical devices, hospitals appli- 
ances, babies' toys, hospital appliances, surgical apparatus, food and beverages packaging, textiles industry, and many other daily life usages [39-41]. The synthesis and applications of antimicrobial materials are exponentially increasing and researchers are trying to find new materials that can inhibit or kill the microbes. Recently, the advent of nanoscale materials finds its numerous applications against bacterial and microbial killing or inhibition. Therefore, these materials are largely studied at both industrial and academic levels because they provided substantial importance to other materials. Once the material is proved as an antimicrobial agent its use and application became extended to other technological sectors. In this study, we have screened the Alg/FP, Alg/FP@Co, Alg-CoNi1/FP@Co, and Alg-CoNi2/FP@Co catalysts against the inhibition of B. subtilis Gram-positive bacterium. The highest zone of inhibition of $2.5 \mathrm{~cm}$ was achieved with Alg-CoNi2/FP@Co NPs and lowest with Alg/FP, which suggested the role of CoNi NPs in Alginate-cellulose filter paper network. Ting Tsai et al. studied the antibacterial activity of cellulose paper fabricated with Ag-coated Au NPs indicating strong antibacterial activity against E. coli JM109. The authors synthesized Ag-coated Au NPs in different sizes, where the particles with $15 \mathrm{~nm}$ showed an excellent antibacterial activity against E. coli [42]. Similarly, bacterial cellulose fabricated with Ag NPs showed good antibacterial potential against E. coli. Thus, it is suggested that cellulose materials can be modified with various inorganic filler to make it an efficient catalyst against bacterial inhibition [43]. The zone of inhibition B. subtilis by all catalysts is provided in Table 1.

Table 1. Zone of inhibition of B. subtilis by all four catalysts.

\begin{tabular}{cc}
\hline Catalyst & Zone of Inhibition $(\mathbf{c m})$ \\
\hline Alg/FP & 0.3 \\
\hline Alg/FP@Co NPs & 1.0 \\
\hline Alg-CoNi1/FP@Co NPs & 1.7 \\
\hline Alg-CoNi2/FP@Co NPs & 2.5 \\
\hline
\end{tabular}

\subsection{Catalyst activity}

\subsubsection{Discoloration of CR Dye}

The as-synthesized Co NPs on the Alg/FP and Alg-CoNi1/FP@Co NPs and AlgCoNi2/FP@Co NPs were used as solid matrix and were applied against the decolorization of CR dye. CR dye appeared at $495 \mathrm{~nm}$ in the UV-Vis. absorbance spectrum. This redshift is due to the presence of the diazo group, which upon treatment with $\mathrm{NaBH}_{4}$ transformed to hydrazine products [44]. A literature survey discovered that $\mathrm{NaBH}_{4}$ can decolorize $\mathrm{CR}$ dye, but the process is too slow and has no economic importance. The process is thermodynamically important, but not kinetically [44,45]. However, metal nanoparticles have proved to have an important effect on the degradation of CR dye. Alg/FP@Co, Alg-CoNi1/FP@Co, and Alg-CoNi2/FP@Co NPs were used against the degradation of CR dye in the presence of $\mathrm{NaBH}_{4}$ as a reducing agent. As discussed earlier, the $\mathrm{NaBH}_{4}$ has a negligible effect on the degradation of CR dye; however, it is thus required for the $\mathrm{CR}$ degradation along with the Co NPs to overcome the activation barrier of the reaction. Briefly, after the addition of the catalyst, there was a decline in the absorbance of $C R$ dye at $\lambda_{\max } 495 \mathrm{~nm}$, and some other peaks were arising at 344, 284, and $244 \mathrm{~nm}$ during the discoloration of CR dye. The appearance of new peaks predicted the formation of byproducts. These new peaks were due to the $-\mathrm{COOH}$ and $-\mathrm{NH}_{2}$ groups, respectively [44]. As manifested in the inset of Figure 3a, the Alg/FP supported Co NPs degraded the CR dye in 20 min with $k_{\text {app }}$ value $1.27 \times 10^{-1} \mathrm{~min}^{-1}$ with a regression coefficient $\mathrm{R}^{2} 0.9382$. The degradation percent of CR was $91.76 \%$ per 20 min (Table 2). Similarly, under the same experimental conditions, 91.65 and $90.41 \%$ of the $\mathrm{CR}$ dye solution was decolorized in 19 and 9 min by Alg-CoNi1/FP@Co and Alg-CoNi2/FP@Co NPs, respectively. The rate constant values of CR discoloration with Alg-CoNi1/FP@Co and Alg-CoNi2/FP@Co NPs were $1.46 \times 10^{-1}, 3.63 \times 10^{-1} \mathrm{~min}^{-1}$, respectively. Based on the $k_{\text {app }}$ values, the superior 
catalyst activity was displayed by Alg-CoNi2/FP@Co NPs compared to Alg/FP@Co NPs and Alg-CoNi1/FP@Co NPs. The UV-Vis. absorbance spectrum of CR dye catalyzed by Alg-CoNi1/FP@Co and Alg-CoNi2/FP@Co NPs manifested in Figure 3b,c, respectively, while the linear relationship based on $\ln _{t} / C_{0}$ vs. time is depicted in Figure $3 d$. The slow rate of Alg/FP supported Co NPs against the degradation of CR dye was due to an induction period $\left(t_{0}\right)$, as shown in Figure $3 \mathrm{~d}$. This period is characterized by the rearrangement of reactive sites of the catalyst such as faces and edges. Once these reactive sites are prepared for the chemical reactions, the rate of reaction is enhanced. A high $t_{0}$ value was observed for Alg/FP@Co NPs as compared to Alg/FP-Co-Ni1@Co NPs and Alg/FP-Co-Ni2@Co $\mathrm{NPs}$, which further support the role of CoNi nanocatalyst in the Alg/FP polymer networks. It is further proposed that during the $\mathrm{CR}$ degradation, $\mathrm{NaBH}_{4}$ and $\mathrm{CR}$ dye get adsorbed on the surface of Co NPs supported on Alg/FP or Alg-CoNi/FP. After the adsorption of $\mathrm{NaBH}_{4}$ and $\mathrm{CR}$ dye, the Co NPs transferred the electrons provided by $\mathrm{NaBH}_{4}$ in the form of $\mathrm{H}^{-1}$ ions to the dyes. Thus, Co NPs supported on the solid matrix provided a vast surface for the $\mathrm{CR}$ dye, $\mathrm{NaBH}_{4}$, and electrons, where they play with each other and degraded the CR dye [46].
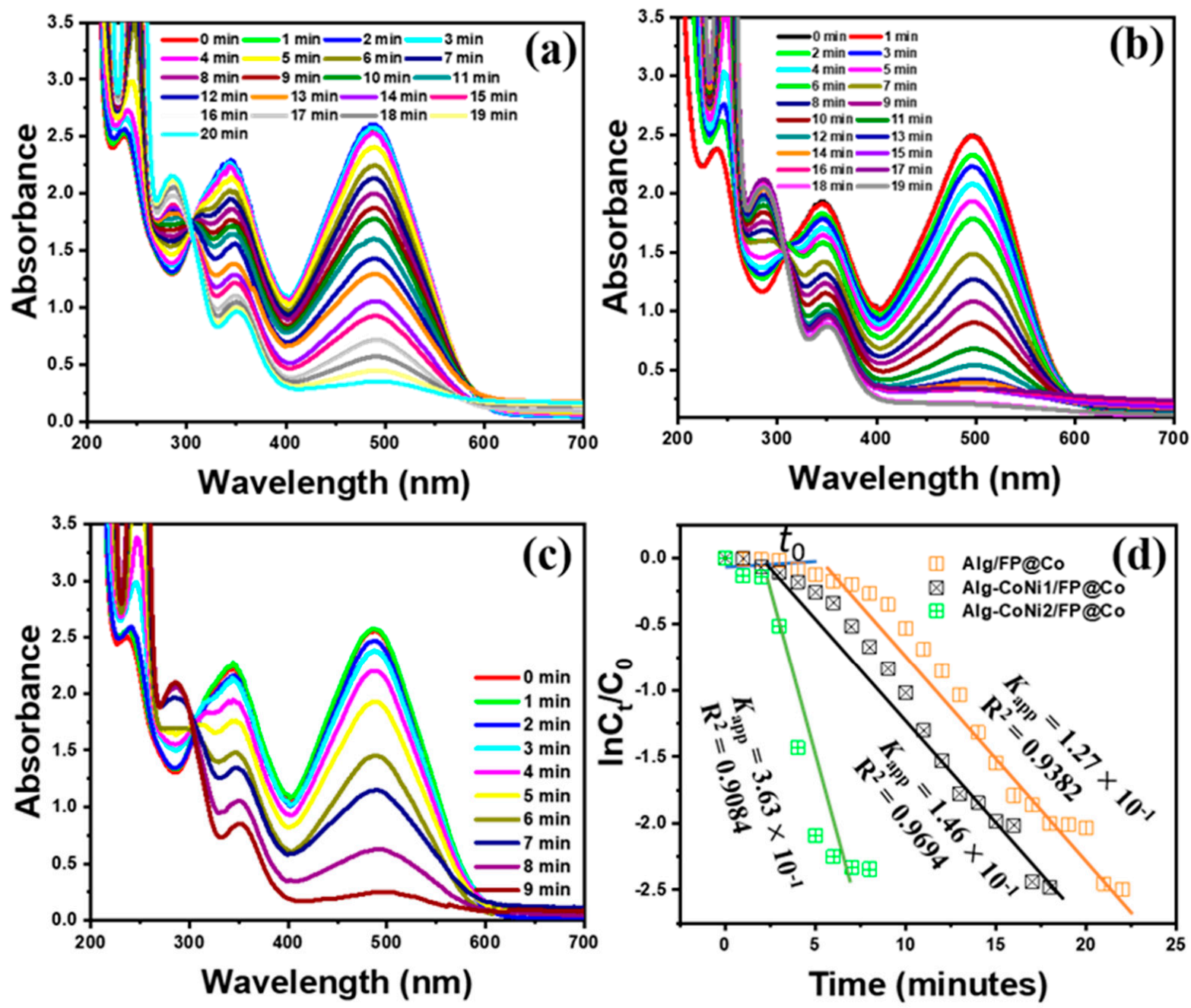

Figure 3. UV-Vis. absorbance spectra of CR dye discoloration in the presence of $\mathrm{NaBH}_{4}$ using Alg/FP@Co (a), AlgCoNi1/FP@Co (b), Alg-CoNi2/FP@Co NPs (c), and linear relationship of pseudo-1st order kinetics (d). 
Table 2. Kinetics parameters based on pseudo-1st order and \% degradation of CR, MO dyes, and 4NP.

\begin{tabular}{|c|c|c|c|c|}
\hline $\begin{array}{l}\text { Targeted } \\
\text { Pollutants }\end{array}$ & Catalyst & $k_{\text {app }}\left(\min ^{-1}\right)$ & $\mathbf{R}^{2}$ & $\%$ Degradation \\
\hline \multirow{3}{*}{$\mathrm{CR}$} & Alg/FP@Co & $1.27 \times 10^{-1}$ & 0.9382 & 91.76 \\
\hline & Alg-CoNi1/FP@Co & $1.46 \times 10^{-1}$ & 0.9694 & 91.65 \\
\hline & Alg-CoNi2/FP@Co & $3.63 \times 10^{-1}$ & 0.9084 & 90.41 \\
\hline \multirow{3}{*}{$\mathrm{MO}$} & Alg/FP@Co & $2.47 \times 10^{-1}$ & 0.9263 & 92.02 \\
\hline & Alg-CoNi1/FP@Co & $3.10 \times 10^{-1}$ & 0.9371 & 91.55 \\
\hline & Alg-CoNi2/FP@Co & $4.68 \times 10^{-1}$ & 0.9376 & 94.22 \\
\hline \multirow{3}{*}{$4 \mathrm{NP}$} & Alg/FP@Co & $1.71 \times 10^{-1}$ & 0.9855 & 92.50 \\
\hline & Alg-CoNi1/FP@Co & $2.56 \times 10^{-1}$ & 0.9636 & 91.06 \\
\hline & Alg-CoNi2/FP@Co & $5.55 \times 10^{-1}$ & 0.9740 & 94.69 \\
\hline
\end{tabular}

After concluding the high catalyst activity of Alg-CoNi/2FP@Co NPs, various factors such as effect of initial dye concentration, the effect of $\mathrm{NaBH}_{4}$ and catalyst amount were studied on the degradation of CR dye by using Alg-CoNi/2FP@Co NPs in the presence of $\mathrm{NaBH}_{4}$.

Effect of Concentration on CR Dye Degradation

Concentration has a major role in the degradation of pollutants because the reaction occurs on the surface of catalyst. It is well-known that increasing the amount of concentration will decrease the rate of reaction because high amount of pollutant molecules is available for the same amount of catalyst. Various concentrations of CR dye such as $0.03,0.05$, and $0.09 \mathrm{mM}$ were studied by using $0.5 \mathrm{~mL}$ of $\mathrm{NaBH}_{4}$ and $30 \mathrm{mg}$ of the Alg-CoNi/2FP@Co NPs (Table 3).

Table 3. Effect of concentration, catalyst dosage, and reducing agent on the discoloration of CR dye using Alg-CoNi2/FP@Co NPs as a dip-catalyst.

\begin{tabular}{|c|c|c|c|c|c|}
\hline Reaction Condition & $\begin{array}{c}\text { Various Reaction } \\
\text { Effect }\end{array}$ & $\begin{array}{l}\text { Reaction } \\
\text { Parameters }\end{array}$ & $k_{\mathrm{app}}\left(\min ^{-1}\right)$ & $\mathbf{R}^{2}$ & \% Degradation \\
\hline \multirow{3}{*}{$0.5 \mathrm{~mL} \mathrm{NaBH}_{4}+30 \mathrm{mg}$ catalyst } & \multirow{3}{*}{ Concentration } & $0.03 \mathrm{mM}$ & $3.63 \times 10^{-1}$ & 0.9568 & 86.8 \\
\hline & & $0.05 \mathrm{mM}$ & $2.57 \times 10^{-1}$ & 0.9139 & 91.65 \\
\hline & & $0.09 \mathrm{mM}$ & $3.63 \times 10^{-1}$ & 0.9084 & 90.41 \\
\hline \multirow{3}{*}{$\begin{array}{l}3 \mathrm{~mL} \text { of } 0.09 \mathrm{mM} \text { CR dye } \\
\text { solution }+30 \mathrm{mg} \text { catalyst }\end{array}$} & \multirow{3}{*}{$\mathrm{NaBH}_{4}(1 \mathrm{mM})$} & $0.5 \mathrm{~mL}$ & $3.63 \times 10^{-1}$ & 0.9084 & 90.42 \\
\hline & & $1 \mathrm{~mL}$ & $3.68 \times 10^{-1}$ & 0.9076 & 89.91 \\
\hline & & $2 \mathrm{~mL}$ & $6.98 \times 10^{-1}$ & 0.9508 & 94.85 \\
\hline \multirow{3}{*}{$\begin{array}{c}3 \mathrm{~mL} \text { of } 0.09 \mathrm{mM} \mathrm{CR} \text { dye } \\
\text { solution }+0.5 \mathrm{~mL} \text { of } 1 \mathrm{mM} \\
\mathrm{NaBH}_{4} \text { solution }\end{array}$} & \multirow{3}{*}{ Catalyst dosage } & $30 \mathrm{mg}$ & $3.68 \times 10^{-1}$ & 0.9084 & 90.42 \\
\hline & & $60 \mathrm{mg}$ & $4.28 \times 10^{-1}$ & 0.8897 & 90.42 \\
\hline & & $90 \mathrm{mg}$ & $5.97 \times 10^{-1}$ & 0.9074 & 93.82 \\
\hline
\end{tabular}

Effect of $\mathrm{NaBH}_{4}$ on the Discoloration of CR Dye

The effect of $\mathrm{NaBH}_{4}$ was studied by changing the volume $(0.5,1$, and $2 \mathrm{~mL})$ of $1 \mathrm{mM} \mathrm{NaBH}_{4}$ solution while keeping the same concentration and volume of CR dye (0.09 mM in $3.5 \mathrm{~mL}$ solution), and $30 \mathrm{mg}$ of the Alg-CoNi/2FP@Co NPs. Increasing the volume of $\mathrm{NaBH}_{4}$ solution from 0.5 to $2 \mathrm{~mL}$, the rate of reaction also enhanced from $3.63 \times 10^{-1}, 3.68 \times 10^{-1}$, and $6.98 \times 10^{-1} \mathrm{~min}^{-1}$, respectively. This indicated that the rate of reaction can be enhanced with increase in volume of $\mathrm{NaBH}_{4}$, which suggests the 
prominent role of $\mathrm{NaBH}_{4}$ in the degradation of $\mathrm{CR}$ dye (Figure 4a and Table 3). According to the Hinshelwood-Langmuir mechanism, both $\mathrm{BH}_{4}{ }^{-}$and reactant adsorbed on the surface of the NPs. Note that the adsorption of $\mathrm{BH}_{4}{ }^{-}$and reactant is a reversible process, which makes competition among both $\mathrm{BH}_{4}{ }^{-}$and reactant for the active sites of the NPs. Therefore, a high concentration of reactant slows down the reaction rate. As is obvious from Table 3, the slow rate was observed with high CR concentration. Similarly, a high volume of $\mathrm{NaBH}_{4}$ increases the rate of reaction. For instance, a $k_{\text {app }} 6.98 \times 10^{-1} \mathrm{~min}^{-1}$ is observed when the amount of $\mathrm{NaBH}_{4}$ is high. Both CR and $\mathrm{BH}_{4}{ }^{-}$accommodate on the surface of NPs in a reversible manner where the $\mathrm{BH}_{4}{ }^{-}$provided surface hydrogen to the $\mathrm{CR}$ and convert it to the hydrazine derivatives. These hydrazine derivatives further degraded the product. After the reaction completion, the product detached from the NPs surface and made it free for the next cycle.
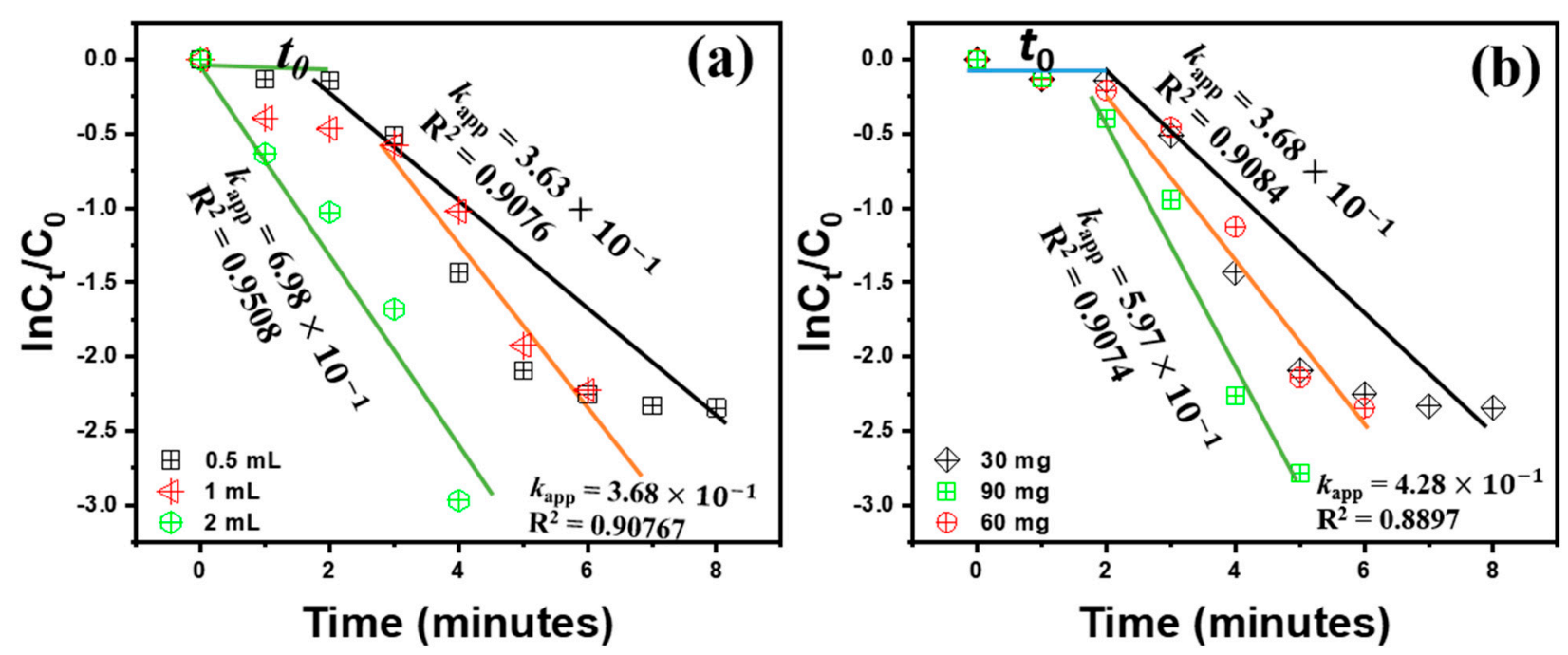

Figure 4. Pseudo first order kinetics plots of $\mathrm{CR}$ dye discoloration under the influence of different amount of $\mathrm{NaBH}_{4}(30 \mathrm{mg}$

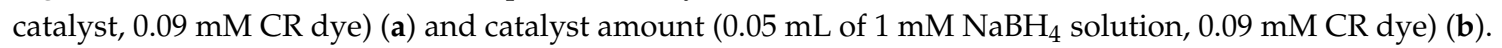

\section{Effect of Catalyst Dosage on the Discoloration of CR Dye}

Optimizing the catalyst amount for the discoloration of reactant is highly desirable in the field of nanocatalysis. Increasing amount of the catalyst will increase the active sites of the catalyst for the molecules. Therefore, the reactant and $\mathrm{BH}_{4}{ }^{-}$accommodate easily on the surface of the catalyst. For instance, 30, 60, and $90 \mathrm{mg}$ of the Alg-CoNi2/FP@Co NPs was used against $C R$ dye degradation under the same experimental conditions. At $90 \mathrm{mg}$, the rate of reaction was $k_{\text {app }} 5.97 \times 10^{-1} \mathrm{~min}^{-1}$ compared to $3.68 \times 10^{-1} \mathrm{~min}^{-1}$ with $30 \mathrm{mg}$ of the catalyst. This suggested that at high amount of the catalyst, the rate of reaction is also high owing to the availability of more active sites for reaction (Table 3 and Figure $4 b$ ).

\subsubsection{Discoloration of MO Dye}

Similar experiments were also conducted for MO dye discoloration for evaluating all the catalysts activity as discussed for $\mathrm{CR}$ dye degradation. As clear from the absorbance spectrum of Figure $5 \mathrm{a}$, the $\mathrm{NaBH}_{4}$ has a negligible effect on the degradation of MO dye. Therefore, the catalyst was introduced along with $\mathrm{NaBH}_{4}$ for the $\mathrm{MO}$ dye degradation. Initially, we used Alg/FP@Co NPs (Figure 5b), where the MO dye decolorized in $12 \mathrm{~min}$. After that, the effect of CoNi composite was studied on Alg/FP. The catalyst Alg-CoNi1/FP@Co NPs (Figure 5c) has a significant effect where it took $9 \mathrm{~min}$ for MO discoloration. Interestingly, an increased amount of CoNi composite in $\mathrm{Alg} / \mathrm{FP}$ increased the rate of reaction. For instance, Alg-CoNi2/FP@Co NPs decolorized MO dye in 7 min (Figure 5d). During the degradation of $\mathrm{MO}$ dye with all catalysts, it was observed that $\mathrm{MO}$ dye appeared at $\lambda_{\max } 464 \mathrm{~nm}$, which can react with $\mathrm{NaBH}_{4}$ to make their hydrazine product. The hy- 
drazine product is oxidized after the addition of the respective catalyst and a new peak ascends at $\lambda_{\max } 251 \mathrm{~nm}$, which is due to the formation of an amine functional group. The linear relationship $\ln _{\mathrm{t}} / \mathrm{C}_{0}$ vs. $\mathrm{t}$ (Figure $5 \mathrm{e}$ ) indicates the superior catalyst activity of AlgCoNi2/FP@Co NPs with $k_{\text {app }} 4.68 \times 10^{-1} \mathrm{~min}^{-1}$. An induction period $t_{0}$ was observed in the degradation of $\mathrm{MO}$ dye. This time mainly encounters in catalysis reactions where the surface atoms organize themselves and expose their active sites such as faces, edges, and planes. Therefore, after this period the active sites become ready and the catalyst react very fast. Thus, induction period is very important for such a catalyst system. The percent degradation of $\mathrm{MO}$ dye with the respective catalyst indicated that approximately $7 \%$ of MO dye was degraded in 12 min by $\mathrm{NaBH}_{4}$ alone, while in the same time Alg/FP@Co NPs degraded $92 \%$ dye in the presence of $\mathrm{NaBH}_{4}$. Similarly, 91 and $94 \%$ efficiency was achieved with Alg-CoNi1/FP@Co and Alg-CoNi2/FP@Co NPs in 9 and 7 min, respectively (Figure 6f). This indicated that $\mathrm{NaBH}_{4}$ alone cannot change the reaction, while the catalyst brought an actual change in the reactant nature. The present work for $\mathrm{CR}, \mathrm{MO}$, and $4 \mathrm{NP}$ was compared with the literature data as shown in Table 4.

Table 4. Comparative literature data for $\mathrm{CR}, \mathrm{MO}$, and $4 \mathrm{NP}$ degradation with the present data.

\begin{tabular}{|c|c|c|c|c|c|}
\hline Catalyst & $\begin{array}{l}\text { Targeted } \\
\text { Pollutant }\end{array}$ & $\begin{array}{c}\text { Concentration } \\
(\mathrm{mg} / \mathrm{L})\end{array}$ & $\begin{array}{c}\text { Amount of } \\
\text { Catalyst (g/L) }\end{array}$ & \% Discoloration & References \\
\hline CA-PS-ZnO & \multirow{4}{*}{ CR } & 50.00 & - & 95.0 & [47] \\
\hline $\mathrm{Ba} / \mathrm{Alg} / \mathrm{CMC} / \mathrm{TiO}_{2}$ & & 30.00 & 1.20 & 95.0 & [48] \\
\hline $\mathrm{Ba} / \mathrm{Alg} / \mathrm{CMC}$ & & 30.00 & 1.20 & 58.0 & [48] \\
\hline Alg-CoNi2/FP@Co & & 48.72 & 8.44 & 90.4 & Present work \\
\hline cellulose $/ \mathrm{TiO}_{2}$ monolith & \multirow{3}{*}{$\mathrm{MO}$} & 20.00 & 0.19 & - & [49] \\
\hline PtNPs@KWP & & 20.00 & - & 99.0 & [50] \\
\hline Alg-CoNi2/FP@Co & & 22.89 & 8.44 & 94.2 & Present work \\
\hline CelA_C2-F-5\% & \multirow{2}{*}{$4 \mathrm{NP}$} & 0.10 & 10.0 & 85.7 & [51] \\
\hline Alg-CoNi2/FP@Co & & 21.00 & 8.44 & 94.6 & Present work \\
\hline
\end{tabular}

\subsubsection{Reduction of $4 \mathrm{NP}$}

$4 \mathrm{NP}$ is considered a benchmark reaction for the evaluation of such a catalyst system. Therefore, all the catalyst was applied for the reduction of 4NP under a similar experimental procedure discussed above for $\mathrm{CR}$ and $\mathrm{MO}$ dyes degradation. $4 \mathrm{NP}$ is a toxic aromatic compound and strict restriction has been made on their use beyond the permissible limit, which was clariefied by the United State Enviornmental Protection Agency (U.S. EPA). This restriction is implemented on the use of nitrophenols because of their mutagenic and carcinogenic effect, as well as their adverse effect on lungs, kidneys, and CNS.

It was studied in detail that neither borohydride nor catalyst alone reduced nitrophenol because of the high activation barrier requirements. However, both catalyst and $\mathrm{NaBH}_{4}$ together reduced the 4NP easily. As seen in the Figure 6a, Alg/FP@Co NPs can reduce $4 \mathrm{NP}$ to 4 -aminophenol (4AmP) in $16 \mathrm{~min}$, while Alg-CoNi1/FP@Co (Figure 6b) and AlgCoNi2/FP@Co NPs (Figure 6c) took 10 and 6 min respectively, which further support the superior catalyst activity of Alg-CoNi2/FP@Co NPs. As depicted in all the absorbance spectra $4 \mathrm{NP}(318 \mathrm{~nm})$ converted to 4 -nitrophenolateanion having a $\lambda_{\max }$ value of $400 \mathrm{~nm}$. Over time, the absorbance peak at $400 \mathrm{~nm}$ and their deep yellow color vanished with the rise of a new peak at $290 \mathrm{~nm}$. This new peak is the indication of 4-AmP product [52,53]. Figure $6 \mathrm{~d}$ exhibited a relationship of $\ln _{t} / C_{0}$ vs. time, which shows the highest rate constant value of $5.55 \times 10^{-1} \mathrm{~min}^{-1}$ for Alg-CoNi2/FP@Co NPs. 

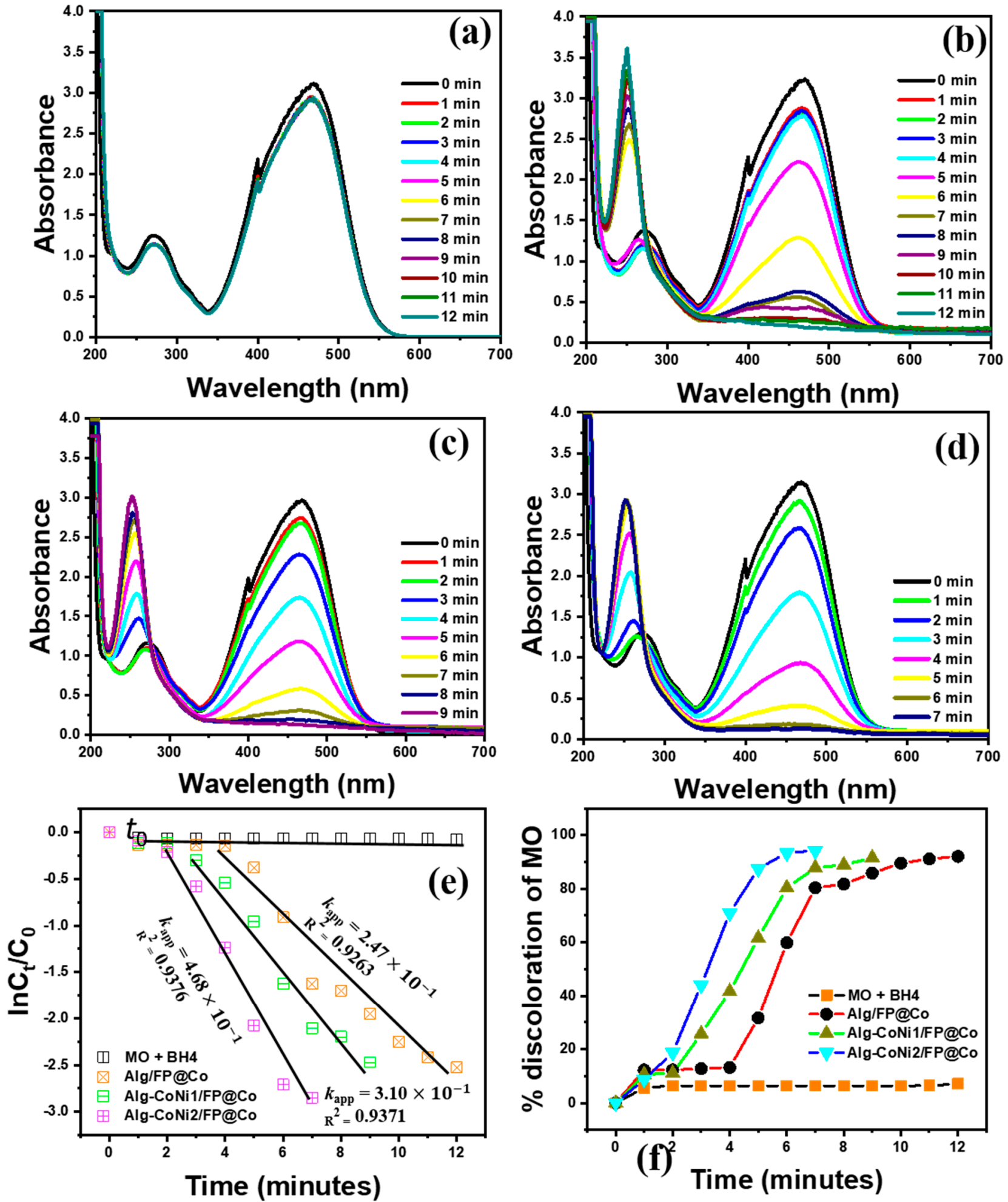

Figure 5. UV-Vis. absorbance spectra of $\mathrm{MO}$ dye discoloration in the presence of $\mathrm{NaBH}_{4}(\mathbf{a})$, and $\mathrm{Alg} / \mathrm{FP} @ \mathrm{Co}(\mathbf{b})$, AlgCoNi1/FP@Co (c), and Alg-CoNi2/FP@Co NPs (d), linear relationship of pseudo-1st order kinetics (e), and percent degradation of the $\mathrm{MO}$ dye (f). 

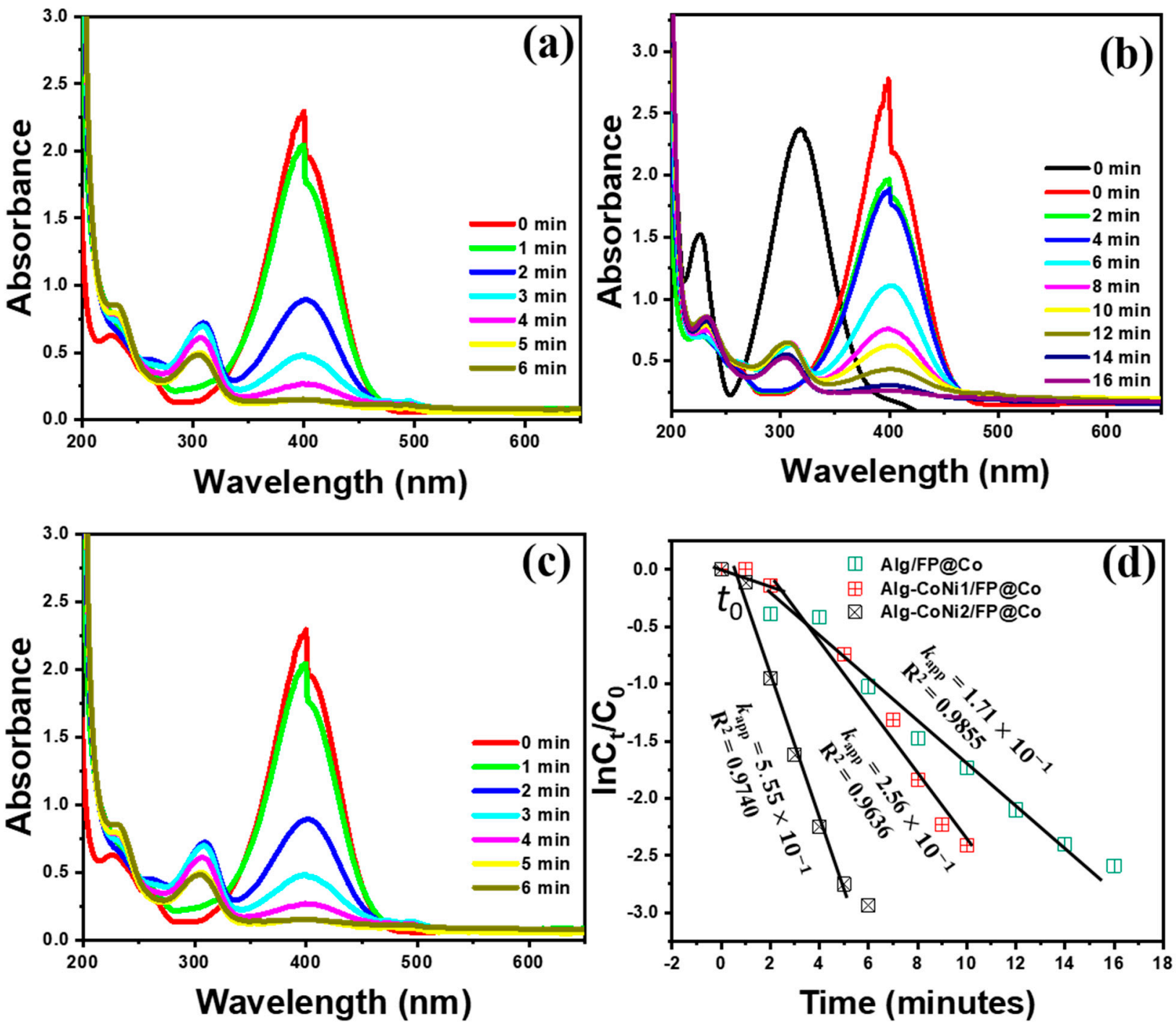

Figure 6. UV-Vis. absorbance spectra of 4NP reduction in the presence of $\mathrm{NaBH}_{4}$ using Alg/FP@Co (a), Alg-CoNi1/FP@Co (b), and Alg-CoNi2/FP@Co NPs (c), and linear relationship of pseudo-1st order kinetics (d).

Based on the discoloration/reduction of azo dyes and nitrophenol it is inferred that CoNi composite played an important role in the reaction and facilitated the transfer of electrons for the degradation/reduction process.

\section{Conclusions}

In the current study, various solid supports comprised of Alg/FP, Alg-CoNi1/FP, and $\mathrm{Alg} / \mathrm{CoNi2} / \mathrm{FP}$ were designed for the stabilization of zero-valent Co NPs. The assynthesized catalysts were used for the inhibition of B. subtilis, and the result revealed that Alg-CoNi2/FP@Co NPs exhibited the highest activity by inhibiting the bacterium zone to $2.5 \mathrm{~cm}$. Furthermore, these catalysts were used as a dip-catalyst for the degradation of CR and $\mathrm{MO}$ dyes and reduction of $4 \mathrm{NP}$. It was revealed that increasing the amount of CoNi nanocomposite increased the bacterial inhibition as well as the rate of dyes degradation and reduction of $4 \mathrm{NP}$. These results suggest that CoNi nanocomposite has a major role in the polymer network for the chemical and biological studies. The CoNi nanocomposite probably facilitates the movement of electrons for the degradation of dyes. The rate constant values were deduced from the pseudo-first-order kinetics. The highest rate was displayed by Alg-CoNi2/FP@Co NPs for MO dye, which was $4.68 \times 10^{-1} \mathrm{~min}^{-1}$. Similarly, the $k_{\text {app }}$ of Alg-CoNi2/FP@Co NPs against the degradation of CR dye is $3.63 \times 10^{-1} \mathrm{~min}^{-1}$ and 
lowest shown by Alg/FP@Co NPs. Among these different catalysts, Alg-CoNi2/FP@Co NPs displayed the highest activity against both chemical and biological activities.

Author Contributions: Conceptualization, Y.A., W.U.R., and S.A.K.; methodology, W.U.R., and S.A.K.; software, S.A.K.; validation, Y.A., W.U.R., H.S.H.M.A., H.A.H., and S.A.K.; formal analysis, S.A.K.; investigation, S.A.K.; resources, Y.A., H.S.H.M.A., and S.A.K.; writing-original draft preparation, S.A.K.; writing-review and editing, Y.A., W.U.R., H.S.H.M.A., H.A.H., and S.A.K.; visualization, Y.A., W.U.R., H.S.H.M.A., H.A.H., and S.A.K.; supervision, S.A.K.; project administration, Y.A., H.S.H.M.A., and S.A.K.; funding acquisition, Y.A., H.S.H.M.A., and S.A.K.; All authors have read and agreed to the published version of the manuscript.

Funding: The Deputyship for Research \& Innovation, Ministry of Education in Saudi Arabia for funding this research work through the project number IFPHI-004-130-2020 and King Abdulaziz University, DSR, Jeddah, Saudi Arabia.

Institutional Review Board Statement: No Human or animal experiment has carried out in this work.

Informed Consent Statement: No human studies has carried out in this project.

Data Availability Statement: N/A.

Acknowledgments: The authors extend their appreciation to the Deputyship for Research \& Innovation, Ministry of Education in Saudi Arabia for funding this research work through the project number IFPHI-004-130-2020 and King Abdulaziz University, DSR, Jeddah, Saudi Arabia.

Conflicts of Interest: The authors declare no conflict of interest.

\section{References}

1. Sapsford, K.E.; Algar, W.R.; Berti, L.; Gemmill, K.B.; Casey, B.J.; Oh, E.; Stewart, M.H.; Medintz, I.L. Functionalizing nanoparticles with biological molecules: Developing chemistries that facilitate nanotechnology. Chem. Rev. 2013, 113, 1904-2074. [CrossRef] [PubMed]

2. Pezzato, C.; Maiti, S.; Chen, J.-Y.; Cazzolaro, A.; Gobbo, C.; Prins, L. Monolayer protected gold nanoparticles with metal-ion binding sites: Functional systems for chemosensing applications. Chem. Commun. 2015, 51, 9922-9931. [CrossRef] [PubMed]

3. Nie, Z.; Petukhova, A.; Kumacheva, E. Properties and emerging applications of self-assembled structures made from inorganic nanoparticles. Nat. Nanotechnol. 2010, 5, 15-25. [CrossRef]

4. Moritz, M.; Geszke-Moritz, M. The newest achievements in synthesis, immobilization and practical applications of antibacterial nanoparticles. Chem. Eng. J. 2013, 228, 596-613. [CrossRef]

5. Khan, S.A.; Ismail, M.; Anwar, Y.; Farooq, A.; Al Johny, B.O.; Akhtar, K.; Shah, Z.A.; Nadeem, M.; Raza, M.A.; Asiri, A.M. A highly efficient and multifunctional biomass supporting $\mathrm{Ag}, \mathrm{Ni}$, and $\mathrm{Cu}$ nanoparticles through wetness impregnation for environmental remediation. Green Process. Synth. 2019, 8, 309-319. [CrossRef]

6. Khan, S.A.; Khan, N.; Irum, U.; Farooq, A.; Asiri, A.M.; Bakhsh, E.M.; Khan, S.B. Cellulose acetate-Ce/Zr@ Cu0 catalyst for the degradation of organic pollutant. Int. J. Biol. Macromol. 2020, 153, 806-816. [CrossRef] [PubMed]

7. Figen, A.K. Improved catalytic performance of metal oxide catalysts fabricated with electrospinning in ammonia borane methanolysis for hydrogen production. Int. J. Hydrog. Energy 2019, 44, 28451-28462. [CrossRef]

8. Khan, S.A.; Khan, S.B.; Asiri, A.M.; Ahmad, I. Zirconia-based catalyst for the one-pot synthesis of coumarin through Pechmann reaction. Nanoscale Res. Lett. 2016, 11, 345. [CrossRef]

9. Sohni, S.; Khan, S.A.; Akhtar, K.; Khan, S.B.; Asiri, A.M.; Hashim, R.; Omar, A.M. Room temperature preparation of lignocellulosic biomass supported heterostructure $(\mathrm{Cu}+\mathrm{Co} @ \mathrm{OPF})$ as highly efficient multifunctional nanocatalyst using wetness co-impregnation. Colloids Surf. A Physicochem. Eng. Asp. 2018, 549, 184-195. [CrossRef]

10. Maslamani, N.; Khan, S.B.; Danish, E.Y.; Bakhsh, E.M.; Zakeeruddin, S.M.; Asiri, A.M. Carboxymethyl cellulose nanocomposite beads as super-efficient catalyst for the reduction of organic and inorganic pollutants. Int. J. Biol. Macromol. 2021, 167, 101-116. [CrossRef]

11. Khan, S.A.; Bakhsh, E.M.; Asiri, A.M.; Khan, S.B. Chitosan coated NiAl layered double hydroxide microsphere templated zero-valent metal NPs for environmental remediation. J. Clean. Prod. 2021, 285, 124830. [CrossRef]

12. Khan, S.A.; Baksh, E.M.; Akhtar, K.; Khan, S.B. A template of cellulose acetate polymer-ZnAl layered double hydroxide composite fabricated with Ni NPs: Applications in the hydrogenation of nitrophenols and dyes degradation. Spectrochim. Acta Part A Mol. Biomol. Spectrosc. 2020, 241, 118671. [CrossRef]

13. Akhtar, K.; Khan, S.A.; Khan, S.B.; Asiri, A.M. Nanomaterials and Environmental Remediation: A Fundamental Overview. Nanomater. Environ. Appl. Fascin. Attrib. 2018, 2, 1-36. 
14. Henry, F.; Marchal, P.; Bouillard, J.; Vignes, A.; Dufaud, O.; Perrin, L. The effect of agglomeration on the emission of particles from nanopowders flow. In Proceedings of the 14th International Symposium on Loss Prevention and Safety Promotion in the Process Industry, Florence, Italy, 12-15 May 2013; pp. 811-816.

15. Subramanian, V.; Ordomsky, V.V.; Legras, B.; Cheng, K.; Cordier, C.; Chernavskii, P.A.; Khodakov, A.Y. Design of iron catalysts supported on carbon-silica composites with enhanced catalytic performance in high-temperature Fischer-Tropsch synthesis. Catal. Sci. Technol. 2016, 6, 4953-4961. [CrossRef]

16. Zhao, Y.; Yang, K.R.; Wang, Z.; Yan, X.; Cao, S.; Ye, Y.; Dong, Q.; Zhang, X.; Thorne, J.E.; Jin, L. Stable iridium dinuclear heterogeneous catalysts supported on metal-oxide substrate for solar water oxidation. Proc. Natl. Acad. Sci. USA 2018, 115, 2902-2907. [CrossRef] [PubMed]

17. Guo, X.; Hao, C.; Jin, G.; Zhu, H.Y.; Guo, X.Y. Copper nanoparticles on graphene support: An efficient photocatalyst for coupling of nitroaromatics in visible light. Angew. Chem. Int. Ed. 2014, 53, 1973-1977. [CrossRef] [PubMed]

18. Chun, Y.S.; Shin, J.Y.; Song, C.E.; Lee, S.-g. Palladium nanoparticles supported onto ionic carbon nanotubes as robust recyclable catalysts in an ionic liquid. Chem. Commun. 2008, 8, 942-944. [CrossRef] [PubMed]

19. Chen, C.W.; Chen, M.Q.; Serizawa, T.; Akashi, M. In-situ formation of silver nanoparticles on poly (N-isopropylacrylamide)-coated polystyrene microspheres. Adv. Mater. 1998, 10, 1122-1126. [CrossRef]

20. Kamal, T.; Khan, S.B.; Asiri, A.M. Synthesis of zero-valent Cu nanoparticles in the chitosan coating layer on cellulose microfibers: Evaluation of azo dyes catalytic reduction. Cellulose 2016, 23, 1911-1923. [CrossRef]

21. Khan, S.A.; Khan, S.B.; Farooq, A.; Asiri, A.M. A facile synthesis of CuAg nanoparticles on highly porous ZnO/carbon blackcellulose acetate sheets for nitroarene and azo dyes reduction/degradation. Int. J. Biol. Macromol. 2019, 130, 288-299. [CrossRef]

22. Saha, S.; Pal, A.; Kundu, S.; Basu, S.; Pal, T. Photochemical green synthesis of calcium-alginate-stabilized Ag and Au nanoparticles and their catalytic application to 4-nitrophenol reduction. Langmuir 2010, 26, 2885-2893. [CrossRef] [PubMed]

23. Mohammadi, P.; Heravi, M.; Daraie, M. Ag nanoparticles immobilized on new magnetic alginate halloysite as a recoverable catalyst for reduction of nitroaromatics in aqueous media. Sci. Rep. 2021, 11, 17124. [CrossRef]

24. Khan, S.B.; Ahmad, S.; Kamal, T.; Asiri, A.M.; Bakhsh, E.M. Metal nanoparticles decorated sodium alginate-carbon nitride composite beads as effective catalyst for the reduction of organic pollutants. Int. J. Biol. Macromol. 2020, 164, 1087-1098. [CrossRef] [PubMed]

25. Al-Ghamdi, Y.O.; Khan, S.A. Stabilization of zero-valent Au nanoparticles on carboxymethyl cellulose layer coated on chitosanCBV 780 zeolite Y sheets: Assessment in the reduction of 4-nitrophenol and dyes. Cellulose 2020, 27, 8827-8841. [CrossRef]

26. Uberoi, V.; Bhattacharya, S.K. Toxicity and degradability of nitrophenols in anaerobic systems. Water Environ. Res. 1997, 69, 146-156. [CrossRef]

27. Brecken-Folse, J.A.; Mayer, F.L.; Pedigo, L.E.; Marking, L.L. Acute toxicity of 4-nitrophenol, 2,4-dinitrophenol, terbufos and trichlorfon to grass shrimp (Palaemonetes spp.) and sheepshead minnows (Cyprinodon variegatus) as affected by salinity and temperature. Environ. Toxicol. Chem. Int. J. 1994, 13, 67-77. [CrossRef]

28. Ahmed, M.S.; Kamal, T.; Khan, S.A.; Anwar, Y.; Saeed, M.T.; Asiri, A.M.; Khan, S.B. Assessment of Anti-bacterial Ni-Al/chitosan Composite Spheres for Adsorption Assisted Photo-Degradation of Organic Pollutants. Curr. Nanosci. 2016, 12, 569-575. [CrossRef]

29. Khan, S.A.; Khan, S.B.; Kamal, T.; Yasir, M.; Asiri, A.M. Antibacterial nanocomposites based on chitosan/Co-MCM as a selective and efficient adsorbent for organic dyes. Int. J. Biol. Macromol. 2016, 91, 744-751. [CrossRef]

30. Hussain, S.; Kamran, M.; Khan, S.A.; Shaheen, K.; Shah, Z.; Suo, H.; Khan, Q.; Shah, A.B.; Rehman, W.U.; Al-Ghamdi, Y.O. Adsorption, kinetics and thermodynamics studies of methyl orange dye sequestration through chitosan composites films. Int. J. Biol. Macromol. 2021, 168, 383-394. [CrossRef]

31. Gičević, A.; Hindija, L.; Karačić, A. Toxicity of azo dyes in pharmaceutical industry. In Proceedings of the International Conference on Medical and Biological Engineering, Banja Luka, Bosnia, 16-18 May 2019; pp. 581-587.

32. Brown, M.A.; De Vito, S.C. Predicting azo dye toxicity. Crit. Rev. Environ. Sci. Technol. 1993, 23, 249-324. [CrossRef]

33. Ahmad, Z.; Shah, S.A.; Khattak, I.; Ullah, H.; Khan, A.A.; Shah, R.A.; Khan, S.A.; Khan, S.B. Melia Azedarach impregnated Co and Ni zero-valent metal nanoparticles for organic pollutants degradation: Validation of experiments through statistical analysis. J. Mater. Sci. Mater. Electron. 2020, 31, 16938-16950. [CrossRef]

34. Hudzicki, J. Kirby-Bauer Disk Diffusion Susceptibility Test Protocol; American Society for Microbiology: Washington, DC, USA, 2009.

35. Hospodarova, V.; Singovszka, E.; Stevulova, N. Characterization of cellulosic fibers by FTIR spectroscopy for their further implementation to building materials. Am. J. Anal. Chem. 2018, 9, 303-310. [CrossRef]

36. Khan, S.A.; Khan, S.B.; Khan, L.U.; Farooq, A.; Akhtar, K.; Asiri, A.M. Fourier Transform Infrared Spectroscopy: Fundamentals and Application in Functional Groups and Nanomaterials Characterization. In Handbook of Materials Characterization; Springer: Berlin/Heidelberg, Germany, 2018; pp. 317-344.

37. Kamal, T.; Khan, S.B.; Haider, S.; Alghamdi, Y.G.; Asiri, A.M. Thin layer chitosan-coated cellulose filter paper as substrate for immobilization of catalytic cobalt nanoparticles. Int. J. Biol. Macromol. 2017, 104, 56-62. [CrossRef]

38. Zhu, J.; Hu, G.; Zhang, J. Preparation of Sn-Cu-graphene nanocomposites with superior reversible lithium ion storage. Mater. Lett. 2016, 185, 565-568. [CrossRef]

39. Fleming, K.; Randle, J. Toys-friend or foe? A study of infection risk in paediatric intensive care unit. Paediatr. Nurs. 2006, 18, 14-18. [CrossRef] [PubMed] 
40. Mokoena, M.P.; Mutanda, T.; Olaniran, A.O. Perspectives on the probiotic potential of lactic acid bacteria from African traditional fermented foods and beverages. Food Nutr. Res. 2016, 60, 29630. [CrossRef]

41. Bello, B.A.; Khan, S.A.; Khan, J.A.; Syed, F.Q.; Mirza, M.B.; Shah, L.; Khan, S.B. Anticancer, antibacterial and pollutant degradation potential of silver nanoparticles from Hyphaene thebaica. Biochem. Biophys. Res. Commun. 2017, 490, 889-894. [CrossRef] [PubMed]

42. Tsai, T.-T.; Huang, T.-H.; Chang, C.-J.; Ho, N.Y.-J.; Tseng, Y.-T.; Chen, C.-F. Antibacterial cellulose paper made with silver-coated gold nanoparticles. Sci. Rep. 2017, 7, 3155. [CrossRef] [PubMed]

43. Pal, S.; Nisi, R.; Stoppa, M.; Licciulli, A. Silver-functionalized bacterial cellulose as antibacterial membrane for wound-healing applications. ACS Omega 2017, 2, 3632-3639. [CrossRef] [PubMed]

44. Ali, H.S.H.M.; Khan, S.A. Stabilization of Various Zero-Valent Metal Nanoparticles on a Superabsorbent Polymer for the Removal of Dyes, Nitrophenol, and Pathogenic Bacteria. ACS Omega 2020, 5, 7379-7391. [CrossRef]

45. Ali, H.S.M.; Anwar, Y.; Khan, S.A. Vigna radiata Impregnated Zero-Valent CuAg NPs: Applications in Nitrophenols Reduction, Dyes Discoloration and Antibacterial Activity. J. Clust. Sci. 2021. [CrossRef]

46. Wunder, S.; Polzer, F.; Lu, Y.; Mei, Y.; Ballauff, M. Kinetic analysis of catalytic reduction of 4-nitrophenol by metallic nanoparticles immobilized in spherical polyelectrolyte brushes. J. Phys. Chem. C 2010, 114, 8814-8820. [CrossRef]

47. Rajeswari, A.; Christy, E.J.S.; Pius, A. New insight of hybrid membrane to degrade Congo red and Reactive yellow under sunlight. J. Photochem. Photobiol. B Biol. 2018, 179, 7-17. [CrossRef]

48. Thomas, M.; Naikoo, G.A.; Sheikh, M.U.D.; Bano, M.; Khan, F. Effective photocatalytic degradation of Congo red dye using alginate/carboxymethyl cellulose/TiO2 nanocomposite hydrogel under direct sunlight irradiation. J. Photochem. Photobiol. A Chem. 2016, 327, 33-43. [CrossRef]

49. Lucchini, M.A.; Lizundia, E.; Moser, S.; Niederberger, M.; Nystrom, G. Titania-cellulose hybrid monolith for in-flow purification of water under solar illumination. ACS Appl. Mater. Interfaces 2018, 10, 29599-29607. [CrossRef] [PubMed]

50. Islam, M.T.; Rosales, J.A.; Saenz-Arana, R.; Ghadimi, S.J.; Noveron, J.C. Rapid synthesis of ultrasmall platinum nanoparticles supported on macroporous cellulose fibers for catalysis. Nanoscale Adv. 2019, 1, 2953-2964. [CrossRef]

51. Melinte, V.; Chibac-Scutaru, A.-L.; Culica, M.E.; Coseri, S. Mineralization versus photoreduction of 4-nitrophenol under the influence of surface functionalized $\mathrm{CeO}_{2}$ nanoparticles, hosted by versatile cellulose supports. Appl. Surf. Sci. 2021, 565, 150494. [CrossRef]

52. Lizundia, E.; Jimenez, M.; Altorfer, C.; Niederberger, M.; Caseri, W. Electroless plating of platinum nanoparticles onto mesoporous cellulose films for catalytically active free-standing materials. Cellulose 2019, 26, 5513-5527. [CrossRef]

53. Anwar, Y.; Ullah, I.; Ul-Islam, M.; Alghamdi, K.M.; Khalil, A.; Kamal, T. Adopting a green method for the synthesis of gold nanoparticles on cotton cloth for antimicrobial and environmental applications. Arab. J. Chem. 2021, 14, 103327. [CrossRef] 